\title{
Indicadores de Qualidade na Administração Municipal: um Estudo Exploratório na Prefeitura da Cidade de Recife
}

\author{
Marcelo Milano Falcão Vieira \\ Sônia Maria Rodrigues Calado \\ Diogo Gonçalves Veras de Morais \\ Stella Maria Medeiros de Araújo \\ Fernando Pontual de Souza Leão
}

\section{ResUMO}

Neste artigo discute-se como analisar práticas de administração da qualidade em organizações públicas. Argumenta-se que esta é uma questão complexa, uma vez que existem poucos elementos objetivos que permitam definições e medidas concretas. Entretanto, se qualidade está, em última análise, relacionada com a percepção de algo bom, salienta-se que a percepção de grupos organizacionais em relação a práticas de qualidade pode oferecer elementos úteis para o entendimento da questão. Através de um estudo teórico-empírico, procura-se identificar os elementos significativos da definição de qualidade para a administração direta da cidade de Recife (PE) na gestão 1997-2000, bem como analisar a lógica e a consistência em que se fundamentam. Os dados foram coletados por meio de entrevistas semi-estruturadas e análise documental e analisados de forma descritivo-interpretativa. Os resultados apontam para uma série de indicadores de qualidade, agrupados em três dimensões: estrutural, recursos humanos e política. Conclui-se com sugestões para a introdução de programas de qualidade e para a avaliação do desempenho da administração municipal.

Palavras-chaves: indicadores de qualidade; qualidade no serviço público; administração municipal.

\begin{abstract}
This paper discusses how to analyse quality management practices in public organizations. We argue that this is a rather complex issue, since there are few objective elements that allow accurate definitions and measures. However, if it is true that quality is related to the perception of something good, than the perception of organizational groups has to be taken into consideration. This study aims to investigate significant components of quality definition for the management of the city of Recife, PE, Brazil, according to their county governors. Data were gathered by means of openended interviews and documentary analysis, and were analysed in a qualitative way. The results show three main dimensions of quality with a group of specific indicators for each one. We conclude with some suggestions for the introduction of quality management programmes and for evaluation of public management performance.
\end{abstract}

Key words: quality indicators; quality in public services; public management. 


\section{INTRODUÇĀO}

Um dos temas que tem sido foco de atenção na literatura de análise organizacional da última década é o gerenciamento da qualidade. Quando as primeiras idéias a respeito do assunto começaram a ser publicadas em forma de livros e artigos científicos, muitos profissionais, acadêmicos ou não, defendiam a idéia de que isto seria novo modismo fadado ao esquecimento. Entretanto o gerenciamento da qualidade cresceu em importância como tema de investigação e, em alguns países industrializados, particularmente nos Estados Unidos, recebeu o status de movimento social (Hackman e Wageman, 1995).

O gerenciamento da qualidade espalhou-se das suas origens nas organizações manufatureiras para todos os tipos de serviços e empreendimentos públicos. Isto deve-se, talvez, ao fato de que o gerenciamento da qualidade não é fenômeno isolado. Alguns autores têm argumentado que ele é importante componente da nova era de globalização econômica e de novas relações de mercado (Piore e Sabel, 1984; Hill, 1991a, 1991b). Mercados nacionais e internacionais têm dispensado crescente atenção à modernização, o que tem levado as organizações a buscarem novos padrões de desempenho. Gerenciamento da qualidade, e qualidade total, especialização flexível, just-in-time e outros conceitos relacionados estão no centro deste contexto de modernização.

A maioria dos trabalhos sobre gerenciamento da qualidade têm sido realizados em organizações envolvidas em algum programa formal de gerenciamento da qualidade. Existem, entretanto, organizações que não se encontram envolvidas em tais programas. Além disso, há organizações em que o conceito de consumidor e cliente é controverso; por exemplo, prisões, asilos, organizações militares e organizações públicas em geral. Nestes casos, a definição e medida de qualidade por meio da satisfação dos consumidores é, no mínimo, problemática. Mesmo uma definição de qualidade mais genérica como conformidade às exigências, também comum na literatura gerencial (e. g. Oakland, 1989), não parece aplicável, quando se levanta o argumento da missão fundamental da organização com objetivos conflitantes; haja vista a constante tensão entre objetivos de custódia e de reabilitação nas prisões, ou objetivos de educação e politização em relação à simples transmissão de uma doutrina religiosa pela igreja. É este tipo de organização que constitui o interesse central deste trabalho, porquanto se considera que as 
administrações municipais são constituídas por diferentes coalizões que representam objetivos múltiplos e muitas vezes conflitantes.

Uma vez que qualidade é conceito abstrato, considerado característica intrínseca de alguma coisa, este tipo de organização também tem, mesmo que de forma implícita, uma idéia do que possui ou não qualidade em relação às atividades que ela desenvolve.

A questão de como analisar práticas de qualidade neste tipo de organização é muito complexa, uma vez que existem poucos elementos objetivos que permitam definições e medidas específicas. Entretanto, se qualidade está, em última análise, relacionada com a percepção de algo bom, a percepção de grupos organizacionais em relação a práticas de qualidade pode oferecer elementos úteis para o entendimento da questão (Vieira, 1997). Assim, considerando a subjetividade ligada ao conceito de qualidade, pode-se afirmar que ele possui caráter valorativo, que gera diferentes noções e significados; estes, por sua vez, originam "diferentes caminhos para sua operacionalização" (Pollitt e Bouckaert, 1995, p. 3)

Levando em conta os assuntos anteriormente relacionados, a presente pesquisa visa à investigação dos elementos que definem qualidade na administração direta da cidade de Recife (PE), na gestão 1997-2000. Esta investigação dá-se a partir da identificação dos elementos significativos da definição de qualidade para a administração direta da cidade de Recife, bem como da identificação e análise da lógica e consistência em que se fundamentam as definições de qualidade.

Uma vez que o gerenciamento da qualidade se tornou um dos temas centrais da literatura em administração, é importante elucidar aspectos relacionados à sua difusão para os setores de serviços e público, áreas diferentes daquela na qual o conceito se originou. $\mathrm{O}$ volume de conhecimento baseado em trabalhos empíricos nessas áreas ainda é pequeno, particularmente no Brasil. Além disso, pode-se argumentar que qualidade foi, e sempre será, tema importante a ser considerado nas atividades organizacionais, mesmo antes da introdução e crescimento do gerenciamento da qualidade como o conceito gerencial dos anos noventa. A literatura especializada na área não contém muita informação empírica sobre práticas de gerenciamento da qualidade em organizações que não estão envolvidas em programas formais ou que têm uma definição de consumidores problemática.

Do ponto de vista prático, este estudo visa a fornecer subsídios para a tomada de decisão dos administradores, bem como oferecer informações úteis para outras organizações públicas de natureza semelhante, que estejam buscando novos padrões de operação e desempenho ${ }^{(1)}$. 


\section{Administraçāo da Qualidade em Organizaçóes Públicas}

Gerenciamento da qualidade não é algo limitado às organizações manufatureiras. Como Lewis e Mitchell (1990, p. 16) argumentam, "a importância de serviços de qualidade é agora bem aceita, e organizações prestadoras de serviços estão dispensando atenção crescente à excelência dos serviços em suas estratégias corporativas e processos de planejamento, na busca de uma vantagem diferencial sobre seus concorrentes". Entretanto, a questão de como uma filosofia e técnica de administração criadas para solucionar problemas de desempenho e competitividade em organizações manufatureiras vêm sendo aplicadas ao setor de serviços, não tem sido saliente na literatura especializada em gerenciamento da qualidade.

Rees (1992) afirma que esta discussão deve ser efetuada em duas partes distintas. Uma está relacionada ao significado ligado ao conceito de qualidade e suas implicações, quando relacionado aos setores de serviço e público. A outra diz respeito ao grau em que técnicas específicas de gerenciamento da qualidade podem ser aplicadas a esses setores.

Os autores da área de qualidade parecem demonstrar um consenso em relação ao fato de qualidade referir-se à satisfação dos consumidores. De acordo com Rees (1992) é relativamente fácil identificar e medir satisfação dos consumidores em termos de um produto tangível. No que se refere à provisão de serviços, entretanto, tal identificação pode ser mais problemática. As características de um serviço, em geral, variam de tangíveis a intangíveis; por exemplo, a aparência do local onde o serviço é oferecido e o grau de acesso e cortesia com o qual o consumidor é tratado (Parasuraman, Zeithaml e Berry, 1985).

Nos últimos anos o gerenciamento da qualidade começou a receber crescente atenção no setor público. Na Grã-Bretanha, por exemplo, várias organizações como a Prefeitura de Strathclyde, região de Glasgow, na Escócia, o Serviço Nacional de Saúde (NHS), e o Serviço Penitenciário Escocês estão envolvidos em programas de gerenciamento da qualidade (Vieira, 1996). Na Espanha o Ministério do Saneamento e Consumo desenvolve um plano de gerenciamento da qualidade para o sistema de saneamento básico daquele país (Ferrándiz, 1992). No Brasil o Governo Federal criou o Programa Brasileiro de Qualidade e Produtividade para organizações públicas e privadas com o objetivo de aumentar a competitividade dos produtos e serviços brasileiros no mercado interno e externo (Brasil, 1990).

Rees (1992) argumenta que algumas especificidades podem dificultar a aplicação de princípios de gerenciamento da qualidade no setor público. Embora qualidade 
no setor público também se refira à satisfação dos consumidores, estes são normalmente o público em geral. Os consumidores são, em outras palavras, um grupo muito maior do que o consumidor imediato de um serviço ou produto. Outra importante distinção apontada por Rees (1992) refere-se ao fato de que a maioria das atividades do setor público estão em uma situação monopolística e, em muitos casos, seus produtos ou serviços são subsidiados. Comparações em relação a melhoramentos na qualidade vêm de padrões estabelecidos por outras partes do setor público ou mesmo do setor privado. Para Rees (1992, p. 73) "padrões definidores dos serviços a serem oferecidos podem ofertar um útil benchmark para avaliação dos presentes serviços e para propor melhoramentos".

Já Swiss (1992) defende a idéia de que iniciativas ortodoxas de gerenciamento da qualidade não são adequadas às organizações governamentais. Esse autor aponta quatro problemas principais que emergem da tentativa de implementação de técnicas de gerenciamento da qualidade no setor público: definição de consumidor; serviços x produtos; foco nos insumos e nos processos; e cultura governamental.

No que se refere à definição de consumidor, Swiss (1992) argumenta que definições específicas de nicho mercado, que habilitam para a clara definição de consumidores, possuem dimensão politicamente controversa no setor público. Isto significa que um nicho pode ter diferentes grupos de potenciais consumidores com objetivos conflitivos. Quando isto acontece, que demandas de grupo o governo deve considerar com mais peso no processo de tomada de decisão? Swiss (1992) afirma que a definição de qualidade baseada na satisfação dos consumidores no setor público depende, em alto grau, da resposta à questão anteriormente colocada. Organizações governamentais têm obrigações que vão além dos interesses dos seus clientes diretos. Algumas vezes, em função da necessidade de cumprir com suas obrigações públicas, elas têm de ser contrárias às necessidades daqueles clientes mais diretos e proteger os interesses mais gerais dos contribuintes. Swiss (1992) também aponta a falta de precisão dos levantamentos de opinião junto ao grande público, no sentido de mensurar o desempenho dos governos e a satisfação dos consumidores de seus serviços. Ele argumenta que tais levantamentos estão sempre sujeitos a pressões da mídia e a questões ideológicas e, portanto, podem refletir uma única dimensão de uma questão maior. Entretanto esses levantamentos e medidas aplicados a clientes mais diretos são importantes como fator a ser considerado no processo de tomada de decisão.

Em termos da diferença entre produtos e serviços, o ponto de vista de Swiss (1992) é similar ao de outros autores que dizem que os serviços são, por exemplo, mais dependentes do trabalhador que está diretamente envolvido em sua oferta, dificultando, assim, a uniformidade de resultados (Parasuraman, Zeithaml e Berry, 1985; Rees, 1992). 
A questão da ênfase nos insumos e nos processos diz respeito à tendência dos programas de qualidade total de forçarem o estabelecimento de medidas de desempenho. Como medidas de resultado no setor público são problemáticas, há a tendência de enfatizar mais os processos, ou seja, os meios, o que para Swiss (1992) pode contribuir para a substituição de objetivos e aumento da burocracia.

A cultura governamental é o quarto problema identificado por Swiss (1992), ao se referir à questão da qualidade no serviço público. Esta relaciona-se à falta de uma cultura forte nas organizações do setor público, causada principalmente pela elevada rotatividade nas posições hierárquicas mais altas. Programas ortodoxos de gerenciamento da qualidade dependem de uma cultura organizacional fortemente voltada para os objetivos do programa de qualidade, seja ele formal ou não, o que implica um comprometimento de longo prazo dos administradores situados nos mais altos níveis da hierarquia organizacional com iniciativas visando à qualidade.

Rago (1994) comenta a necessidade e dificuldade de se adaptarem programas de qualidade total às organizações públicas. Suas razões são, entretanto, diferentes das de Swiss (1992). Ele argumenta que quando se toma uma perspectiva mais estreita de qualidade total, ou seja, quando o nível de análise muda da organização como um todo para o departamento, pelo menos os primeiros três problemas apontados por Swiss (1992) podem ser vencidos. Entretanto, quando relata a experiência de uma organização de saúde nos Estados Unidos, Rago (1994) identifica dois diferentes problemas na aplicação de programas de qualidade ao setor público (o número de consumidores e qualidade x quantidade) e dá apoio ao quarto argumento de Swiss (1992) sobre cultura governamental.

No que diz respeito ao número de consumidores, Rago (1994) argumenta: enquanto no setor privado o aumento no número de consumidores significa aumento no lucro gerado, nas organizações públicas isto significa intensificação do trabalho com o mesmo orçamento. Orçamentos normalmente não seguem o padrão do aumento da demanda para os serviços públicos. Pelo contrário, o aumento no número de consumidores traz uma variedade de problemas administrativos, porque partes da organização se tornam responsáveis pela oferta de mais serviços com os mesmos recursos estruturais, humanos e financeiros.

Rago (1994) também identificou outro problema por ele denominado "dilema qualidade x quantidade". Refere-se ao fato de que, em função de restrições orçamentárias, no que diz respeito à qualidade, a organização pública tem de enfrentar decisões de: (a) aumentar o número de consumidores e atender apenas parte de suas necessidades; ou (b) aumentar o volume de necessidades atendidas dos consumidores já existentes. Isto não ocorre no setor privado em geral, porque os lucros gerados pelo desempenho organizacional direcionam a futura aplicação 
dos recursos. Não há obrigação pública, porque o nicho de mercado de empreendimentos privados é restrito e bem definido.

Embora haja diferenças em relação à natureza dos serviços ou produtos oferecidos pelo setor público, Rees (1992) comenta que os princípios do gerenciamento da qualidade continuam apropriados. Rago (1994) também afirma que, apesar de algumas características peculiares das organizações públicas, é erro acreditar que programas de qualidade total não podem ser integrados com sucesso nesse tipo de organização. Se qualidade se refere à satisfação dos consumidores, não há razão para acreditar que o setor público não possa oferecer serviços ou produtos de acordo com padrões de qualidade predeterminados. Conceitos como garantia da qualidade e cuidado com o consumidor, baseados no princípio de cadeias de qualidade desenvolvido por Oakland (1989), já têm sido amplamente usados em organizações públicas ao redor do mundo (vide Rees [1992, p. 74-80] para exemplos). Além disso, os conceitos relacionados ao lado leve dos programas de qualidade total são passíveis de aplicação ao setor público. Neste sentido, Rees (1992, p. 81) argumenta: "a noção de melhoramento contínuo, como um objetivo a ser alcançado sem nunca ser efetivamente atingido, muda a visão de qualidade de exclusivamente relacionada à diferenciação produto-serviço público-privado em direção a um conceito mais genérico ligado ao melhoramento das atividades organizacionais".

Na mesma linha de argumentação, Swiss (1992) defende que princípios de qualidade total passíveis de aplicação no setor público seriam, por exemplo, feedback dos clientes, melhoramento contínuo e energização (empowerment). Ele argumenta que, "se introduzido sem a preocupação exclusiva de venda de imagem e com sensibilidade para as características singulares dos governos, 'qualidade total adaptada' pode trazer uma contribuição útil para a administração pública contemporânea" (Swiss, 1992, p. 360).

Ainda assim, existe outra questão significativa em relação ao tema qualidade no serviço público que, recentemente, tem ganho espaço nas discussões sobre o assunto. Qualidade refere-se aos processos internos de gestão ou ao impacto do serviço público na sociedade? Isto conduz à discussão das duas dimensões subjacentes às iniciativas de qualidade na administração pública, ou seja, a existência de uma dimensão técnica e de uma dimensão política. Embora ainda predomine a separação entre governo e administração, sendo governo um problema da ciência política e a administração uma questão técnica de operacionalização (Spink, 1993), considera-se que coexistem, nas organizações públicas, a dimensão técnica e a política (Matus, 1996; Huertas, 1996). Offe (1984) identifica a origem da rígida divisão entre a administração e a política a partir do pressuposto de que a eficiência da racionalidade formal está na disjunção total entre as premissas da ação, por 
um lado, e do aparelho que as executa, por outro. Negando a separação entre as dimensões política e técnica no plano operacional, Matus (1996) recomenda que a arte e a técnica de governar consistem em produzir um balanço global positivo entre a eficácia técnica e a política.

O Serviço de Atendimento ao Cidadão de Salvador (SAC) parece exemplificar esta questão. O SAC constitui projeto do governo do Estado da Bahia, cujo objetivo central é a instalação de postos de atendimento aos cidadãos da cidade de Salvador para a oferta de serviços públicos como "obtenção de carteira de trabalho, carteira de identidade, renovação da carteira de habilitação e outros serviços. O objetivo é proporcionar ao cidadão um atendimento com qualidade, economia de tempo e esforço" (Pinho, Santana e Cerqueira, 1997, p. 29). Na perspectiva de Pinho, Santana e Cerqueira (1997), esta iniciativa enquadra-se no contexto da reforma do Estado, mais especificamente no sentido da busca da eficiência administrativa sem, no entanto, aderir a uma abordagem exclusivamente gerencialista. Neste sentido, o conceito de cidadania é relevante e sobrepõe-se ao conceito de cliente. Segundo os autores, essa mudança ocorre "por que se muda a ponta, que é o cidadão. Muda-se o paradigma, se se começa a dar o espírito de cidadania, onde se pode participar, reclamar, dar sugestões" (Pinho, Santana e Cerqueira, 1997, p. 32).

Os autores salientam que tais inovações se inserem no centro de um governo que, em termos ideológicos, se situa no campo conservador, constituído por uma coalizão comandada pelo Partido da Frente Liberal, no período de governo de 1994 a 1998. Este fato parece contraditório com a literatura que aponta que tais iniciativas seriam mais esperadas de governos chamados de esquerda. Entretanto, Pinho, Santana e Cerqueira (1997, p. 33) argumentam:

"não obstante este fato, sente-se nessa iniciativa toda uma necessidade de sintonização com novos parâmetros que passam a reger a modernidade. Assim é que passam a fazer parte do repertório do governo termos como cidadania, participação popular, conselhos comunitários, termos estes muito mais presentes em experiências de governo do chamado campo democrático-popular. Embora revelando um 'medo' ainda presente a imposição dos novos tempos democráticos parece tornar impossível ignorar a nova situação".

Pinho, Santana e Cerqueira (1997) explicam esta situação pelo esgotamento das formas tradicionais de dominação do campo conservador sem, entretanto, desconsiderar a existência de dificuldades e contradições inerentes à implementação de iniciativas dessa ordem em governos conservadores. Pode-se, assim, supor que esta é uma questão que ainda merece análises mais aprofundadas e investigações longitudinais, a fim de se verificar em que grau estas experiências estão 
legitimadas e podem sobreviver a governos municipais com diferentes perspectivas ideológicas, que tendem a tratar a relação entre a dimensão técnica e política das decisões e ações gerenciais de diferentes perspectivas. A mesma observação aplica-se ao caso da experiência do Orçamento Participativo de Porto Alegre, introduzido pelo governo do Partido dos Trabalhadores (PT).

Programas de qualidade total foram primeiramente criados para resolver problemas de desempenho em empresas manufatureiras. Estes programas predizem muitas mudanças no desenho organizacional; a literatura especializada vem tentando analisar tais resultados. Pesquisas nesta área demonstram que os resultados dessas mudanças podem, às vezes, diferir daqueles oferecidos pela literatura gerencial mais prescritiva. Há também certo grau de desacordo entre analistas organizacionais em relação aos efeitos reais de programas de qualidade na organização do trabalho.

Os aspectos que dizem respeito a organizações de manufatura têm sido pesquisados com mais intensidade do que aqueles ligados aos setores de serviços e público. Mesmo assim, como Storey e Sisson $(1989$, p. 116) comentam, a maioria das pesquisas sobre o assunto é baseada na tradição analítica da corrente denominada de "processo de trabalho"; "dados empíricos são normalmente insatisfatórios, e mesmo quando os dados são apresentados, isto é feito mais no sentido de ilustrar teorias do que de testá-las".

Organizações do setor público não têm sido estudadas com a mesma intensidade aplicada às organizações do setor privado. Não há ainda um corpo de conhecimento bem estabelecido sobre como as técnicas de administração da qualidade podem ser aplicadas ao setor público. Há necessidade de pesquisa empírica, especialmente sobre a natureza das mudanças nos princípios de qualidade para que possam ser aplicados com sucesso ao setor público, bem como na identificação de elementos que possam contribuir para o aperfeiçoamento do conceito de qualidade nas organizações públicas.

\section{Delineamento da Pesquisa e Método}

A presente pesquisa foi desenhada com o objetivo de desenvolver um melhor entendimento do conceito de qualidade, no âmbito do serviço público brasileiro, especificamente do poder executivo municipal. Trata-se de estudo de caso do tipo seccional, porquanto se limita ao estudo em profundidade da realidade de uma prefeitura em determinado período de sua história. Uma estratégia de pesquisa qualitativa foi considerada apropriada para este estudo, uma vez que, além de 
oferecer descrições ricas sobre uma realidade específica, ela ajuda o pesquisador a superar concepções iniciais e a gerar ou revisar as estruturas teóricas adotadas previamente (Miles e Huberman, 1994).

A prefeitura escolhida foi a da cidade de Recife (PE). Sendo a população de interesse a equipe de governo, o presente estudo não teve amostra selecionada, pois o objetivo foi entrevistar a totalidade da equipe de primeiro nível: prefeito, vice-prefeito e os 14 secretários municipais ${ }^{(2)}$.

Como mencionado anteriormente, a pesquisa busca definir qualidade no serviço público, na percepção dos respondentes. Para tal foi considerada necessária a realização de uma etapa de preparação ao trabalho de campo composta de dois reconhecimentos prévios. No primeiro elencou-se uma lista de componentes da variável qualidade, com base em literatura disponível, bem como em depoimentos de pessoas consabidamente experientes na área. No segundo reconhecimento prévio, testou-se a referida lista, por meio de um pré-teste que consistiu em um painel de especialistas, ou seja, a lista de componentes do conceito qualidade foi mostrada a especialistas na área de administração pública das Universidades Federais de Pernambuco e de Santa Catarina, onde os autores deste trabalho mantinham contatos sobre o tema da pesquisa, com o objetivo de testar a validade facial da referida lista para a realização das entrevistas e para uma possível elaboração de questionário.

Os dados foram coletados durante os meses de maio, junho e julho de 1997, mediante o uso de entrevistas semi-estruturadas, compostas das seguintes questões: (1) Que significa para o senhor qualidade no serviço público?. (2) Que significa para o senhor qualidade, especificamente no poder executivo municipal?. (3) Que significa para o senhor qualidade, especificamente na secretaria que o senhor dirige?. (4) Até que ponto o senhor acredita poder alcançá-la?. Em função da resposta dada, o entrevistador acrescentava no diálogo os componentes de qualidade da lista previamente elaborada e testada. O tempo de duração das entrevistas variou entre quarenta minutos e uma hora e meia.

O objetivo desta aplicação é multifacetado: (a) as perguntas abertas referentes à definição de qualidade para cada elemento da equipe de governo permite, entre outras coisas, avaliar quão consistentes são as visões de qualidade de cada elemento da equipe, tanto individualmente quanto no nível do grupo; (b) a avaliação de elementos de uma lista de itens previamente elencados permite obter uma mesma visão de consistência, bem como avaliar até que ponto os componentes do conceito oferecidos nas primeiras perguntas são similares ou substancialmente diferentes dos previamente avaliados como importantes; e (c) a pergunta referente à probabilidade de obter sucesso (expectativa) em cada um dos itens analisados 
permite estabelecer a base para um diagnóstico inicial, para ser aprofundado em pesquisa futura.

Foram também utilizados dados secundários coletados nos documentos disponíveis na prefeitura (plano de governo do prefeito municipal, planos de metas de cada secretaria, quando disponíveis, organogramas e outros documentos de caracterização do caso estudado) bem como na mídia, particularmente na imprensa escrita.

Mediante a análise do conteúdo das entrevistas com os secretários municipais da cidade de Recife, bem como com o Vice-Prefeito, que ocupa também a Secretaria de Cultura ${ }^{(3)}$, chegou-se a uma relação de 68 indicadores de qualidade para a administração municipal de forma geral, e a uma média de 5 indicadores específicos para cada secretaria ${ }^{(4)}$. A relação dos 68 indicadores foi novamente submetida a um processo de agrupamento para dados qualitativos (Miles e Huberman, 1994), com o objetivo de estabelecer apenas os elementos significativos e não-repetitivos da definição de qualidade. Chegou-se, assim, a uma relação final de 27 indicadores gerais de qualidade para a administração municipal da cidade de Recife no período de 1997 a 2000.

Os dados foram, finalmente, dispostos em matrizes de conteúdo (Miles e Huberman, 1994), para melhor visualização do resultado final, ademais de discutidos de forma descritivo-qualitativa.

\section{Apresentação e Análise dos Dados}

\section{Caracterização do Caso em Estudo}

A Prefeitura Municipal da Cidade de Recife, gestão 1997-2000, é formada por uma frente partidária que pode ser caracterizada como de centro-direita, composta pelo PFL, PMDB e, minoritariamente, por outros partidos historicamente considerados de direita. A gestão anterior era do PMDB, período no qual a cidade esteve envolvida em um tipo de gestão participativa, mais nos moldes dos governos chamados de esquerda. Entre outras realizações, o planejamento participativo foi instituído com sucesso, os conselhos municipais foram organizados e tornaram-se atuantes; a área da saúde municipal, praticamente inexistente, foi organizada e tornou-se referência do governo; o centro histórico foi revitalizado, tornando a cidade novamente um centro de atração turística e cultural. Tais fatos ganharam relevância; a cidade voltou a ter uma imagem de destaque no cenário 
nacional, tendo seu prefeito sido por diversas vezes escolhido como melhor prefeito do Brasil.

A coalizão com o PFL para disputar o governo municipal teve um objetivo futuro, uma vez que a chance de vitória de uma chapa exclusiva do PMDB nas eleições municipais de 1996 era relativamente alta. A aliança foi realizada tendo em vista a disputa do governo do Estado em 1998, ocasião na qual a aliança se manteria, agora com o ex-prefeito do PMDB como candidato a governador. Isto daria ao candidato do PMDB mais força político-eleitoral, principalmente no interior, para derrotar o possível candidato do PSB (antigo aliado do ex-prefeito), em uma disputa direta para o governo do Estado.

Com algumas mudanças na administração municipal em função das eleições de 1998, o PFL ganha força no decorrer do governo, que passa a possuir mais fortemente características de uma gestão com discurso neoliberal, influenciada pela estrutura social patrimonial e formalística local. A administração municipal tornase mais centralizada, em função das características pessoais do prefeito municipal.

Essa coalizão situacional entre dois grupos com perfis e histórias políticas muito diferentes, pode influenciar nos resultados desta pesquisa, principalmente no que diz respeito à uma relativa inconsistência encontrada na visão geral de qualidade da prefeitura.

\section{Resultados}

O resultado final do agrupamento dos indicadores permitiu a identificação de três dimensões significativas para a definição do conceito de qualidade, que facilitam seu entendimento, bem como a identificação e a análise da lógica subjacente em cada dimensão. Nos Quadros 1, 2 e 3 a seguir, observa-se o resultado final do agrupamento dos indicadores e a identificação da dimensão relativa a cada grupo de indicadores.

A classificação dos indicadores de qualidade nas três dimensões apresentadas nos Quadros 1, 2 e 3 obedeceu a seguinte lógica:

. Dimensão estrutural: incluíram-se nesta dimensão as referências feitas nas entrevistas às questões relativas à estrutura (estrutura física, integração/diferenciação, entre outras) e aos processos organizacionais (mecanismos de coordenação e controle, comunicação, entre outros) da Prefeitura Municipal de Recife.

- Dimensão recursos humanos: nesta dimensão foram incluídas as referências feitas nas entrevistas relacionadas aos aspectos comportamentais da estrutura organizacional da Prefeitura Municipal de Recife (comprometimento organiza- 
cional, por exemplo), bem como às questões referentes à função recursos humanos, como tradicionalmente é tratada na literatura especializada (recrutamento e seleção, treinamento etc).

. Dimensão política: incluíram-se nesta dimensão as referências feitas nas entrevistas aos aspectos que envolvem a ideologia partidária dos gestores, ou que estão mais diretamente influenciados por ela.

Cabe salientar a dificuldade na separação de alguns indicadores em dimensões exclusivas, pois a natureza às vezes multifacetada do indicador permitiria sua classificação em mais de uma categoria. Esta é, entretanto, uma limitação comum dos estudos na área de ciências sociais, que trabalham com tipologias, e acreditase que, no caso desta pesquisa, os critérios utilizados para proceder à categorização foram adequados.

\section{Quadro 1: Indicadores de Qualidade da Administração Municipal da Cidade de Recife - Período 1997-2000: Dimensão Estrutural}

\begin{tabular}{|l|l|}
\hline DIMENSÃO & \multicolumn{1}{|c|}{ INDICADORES } \\
\hline \multirow{5}{*}{ Estrutural } & 1. Flexibilidade e agilidade da estrutura organizacional \\
2. Estrutura organizacional que favoreça a inovação & 3. Comunicação formal eficaz entre as unidades \\
4. Comunicação informal eficaz entre as unidades \\
5. Cooperação entre as unidades \\
6. Planejamento conjunto das unidades \\
7. Parcerias com a iniciativa privada \\
8. Terceirização \\
9. Acompanhamento pessoal pelo titular dos projetos realizados pela \\
sua unidade \\
10. Relatórios para acompanhamento dos projetos \\
11. Orçamento participativo \\
12. Conselhos municipais atuantes \\
13. Continuidade das ações de longo prazo \\
14. Acompanhamento das políticas da unidade mediante índices de \\
pobreza, analfabetismo, mortalidade infantil etc. \\
15. Informatização \\
16. Satisfação da comunidade (público em geral)
\end{tabular}

No que se refere à dimensão estrutural especificamente, observa-se que a estrutura organizacional é aspecto considerado muito relevante pela população pesquisada para que se obtenha uma administração municipal de qualidade (vide Quadro 1). Tendências atuais da estruturação das organizações foram ressaltadas, como, por exemplo, a flexibilidade e agilidade estruturais, a formação de parcerias e a informatização. Entretanto observa-se também que foi salientada a necessidade de comunicação eficaz entre as unidades organizacionais que compõem a 
administração municipal, planejamento conjunto e cooperação. Este fato aponta para um dilema da administração das organizações contemporâneas, tanto no setor público como no setor privado, relativo à flexibilização x integração. De um lado, a busca da flexibilidade como forma de estruturação mais eficaz em face de ambientes turbulentos implica descentralização das decisões e ações administrativas. De outro, há a necessidade de coordenação e controle dessas decisões e ações, o que pode ocasionar centralização. Os indicadores referentes à estrutura organizacional foram os mais citados nas entrevistas entre os que compõem a dimensão estrutural do conceito de qualidade na prefeitura de Recife. Aqui se percebe uma valorização da dimensão técnica do conceito de qualidade, o que parece indicar que alguns elementos componentes dos programas formais de qualidade como a integração, o uso de técnicas que visam a melhorar a estrutura (e o layout) e a transcendência das fronteiras departamentais (Binns, 1993) poderiam ser utilizados para melhorar a qualidade do serviço oferecido.

Um segundo conjunto de indicadores, também considerado importante, foi o de avaliação do desempenho global da organização. Indicadores como acompanhamento dos projetos por meio de supervisão direta e de resultados foram considerados mecanismos de coordenação e controle adequados para a atividade de gestão municipal. Cabe salientar que apenas um secretário destacou a utilização de medidas estatísticas, índices de analfabetismo, mortalidade infantil etc, como indicadores de qualidade. Entretanto, quando ativados pelo entrevistador, esses índices (também chamados de indicadores sociais) foram considerados importantes. Este fato parece demonstrar, também neste aspecto, uma visão mais tecnicista da administração pública, em que o debate entre quais seriam os conceitos adequados para medir desempenho neste setor seria pertinente. Parece haver uma valorização maior da eficiência, no seu sentido clássico, do que da eficácia.

A participação da comunidade forma o terceiro grupo de indicadores da dimensão estrutural. A decisão de adotar a participação popular como estratégia de gestão pública é eminentemente política. Entretanto suas formas de manifestação e operacionalização ocorrem por meio dos arranjos estruturais da organização prefeitura. Os entrevistados consideraram importante para a qualidade da administração municipal o orçamento participativo, instituído na gestão anterior, a organização e atuação dos conselhos municipais e sua interação com a prefeitura, bem como a satisfação da população com os serviços prestados pela administração. Cabe salientar que este conjunto de indicadores foi mais enfatizado pelos secretários do PMDB, partido ao qual pertencia o prefeito da gestão anterior. Apenas um secretário do PFL atribuiu grande importância a esse conjunto de indicadores, antes de sua ativação pelo entrevistador. Este fato parece corroborar, pelo menos do ponto de vista interno da organização, as afirmações de Vieira e 
Carvalho (1999) de que diferentes conceituações de qualidade estruturam-se por meio de objetivos múltiplos.

\section{Quadro 2: Indicadores de Qualidade da Administração Municipal da Cidade de Recife - Período 1997-2000: Dimensão Recursos Humanos}

\begin{tabular}{|c|c|}
\hline DIMENSÃO & INDICADORES \\
\hline Recursos Humanos & $\begin{array}{l}\text { 1. Grau de escolaridade dos funcionários } \\
\text { 2. Experiência profissional dos funcionários } \\
\text { 3. Treinamento } \\
\text { 4. Remuneração adequada dos funcionários } \\
\text { 5. Plano de carreira } \\
\text { 6. Plano de cargos e salários } \\
\text { 7. Orgulho de ser servidor público } \\
\text { 8. Avaliação objetiva do desempenho dos funcionários }\end{array}$ \\
\hline
\end{tabular}

Na dimensão recursos humanos observa-se a importância atribuída pela gestão 1997-2000 da prefeitura de Recife à capacitação do pessoal administrativo (vide Quadro 2). Critérios de seleção e treinamento foram apontados como importantes para a prestação de serviços de qualidade pela prefeitura. Outros indicadores considerados importantes foram a remuneração adequada do servidor, o estabelecimento de um plano de carreira e a criação de um sistema de avaliação objetivo do desempenho do servidor. Foi também muito citada nas entrevistas a necessidade de um programa de treinamento específico, no sentido de restruturar, redimensionar e reavaliar a imagem do servidor público em geral, e municipal em particular, tendo em vista um desgaste da sua imagem junto à comunidade, o que contribui para uma autodepreciação da importância do seu serviço e conseqüente desmotivação. Neste ponto há novamente uma congruência com os argumentos de autores como Dawson e Palmer (1993), Binns (1993) e Pollit e Bouckaert (1995), de que é possível a utilização de ferramentas gerenciais para melhorar a qualidade, principalmente no que se refere à formação de recursos humanos e ao lado leve dos programas de qualidade (Rees, 1992).

Há que se considerar aqui uma estrutura superposta de cargos efetivos, ou seja, as posições ocupadas por funcionários concursados, e cargos comissionados, ou seja, aqueles ocupados por indicação e com contrato temporário. Apesar de considerada importante a capacitação geral dos funcionários, incluindo os que ocupam cargos comissionados, os indicadores desta dimensão, expostos no Quadro 1 , referem-se aos funcionários com cargos efetivos. O pressuposto é de que na escolha dos indicados para os cargos comissionados o critério de qualificação para a função é aceito como dado. Evidentemente este é um argumento que des- 
considera a realidade conflituosa das coalizões de poder do jogo político e parece ser argumento apenas formal.

\section{Quadro 3: Indicadores de Qualidade da Administração Municipal da Cidade de Recife - Período 1997-2000: Dimensão Política}

\begin{tabular}{|c|l|}
\hline DIMENSÃO & \multicolumn{1}{|c|}{ INDICADORES } \\
\hline Política & $\begin{array}{l}\text { 1. Grau de influência político-partidária x grau de influência técnica } \\
\text { nas decisões administrativas } \\
\text { 2. Relação entre cargos comissionados e cargos efetivos } \\
\text { 3. Grau de importância atribuída à necessidade de ampliação (volume } \\
\text { de recursos) do programa de orçamento participativo }\end{array}$ \\
\hline
\end{tabular}

A dimensão política evidencia a existência de indicadores relativos à influência técnica e à influência política nas decisões da administração municipal (vide Quadro 3). Encontram-se também questões relacionadas à importância da existência de cargos comissionados e cargos efetivos e à necessidade de ampliação do volume de recursos destinados ao programa de orçamento participativo. Com relação à importância da influência política e da influência técnica nas decisões e ações governamentais, observou-se uma separação muito clara entre a posição dos secretários do PMDB e a dos demais. Os secretários originários da gestão anterior acreditam que a competência técnica é elemento fundamental para decisões e ações de qualidade, tendo, entretanto, que estar circunscrita a uma visão político-ideológica que oriente a decisão técnica, conforme também argumentam Misoczky, Vieira e Leão (1999). Já os secretários dos demais partidos que compõem a aliança demonstraram tendência a considerar a competência técnica mais importante, sem, entretanto, desconsiderar a relevância da decisão política. Esta visão parece congruente com o ideário neoliberal que, por meio do argumento da isenção técnica, impõe sua visão política.

No que se refere à relação entre cargos comissionados e cargos efetivos, todos os entrevistados consideram importante a existência de cargos comissionados, mas não em grande número. Entretanto, quando a quantidade de cargos comissionados é elevada, ela é justificada pela pouca capacitação técnica dos servidores com cargo efetivo.

A ampliação do volume de recursos destinados ao programa de orçamento participativo foi considerada como indicador de qualidade pela maioria dos entrevistados, mas foi também mais enfatizada pelos secretários do PMDB. Entretanto a maioria admitiu que a ampliação desse programa está limitada pela capacidade orçamentária do município. 
O grande número de indicadores expostos nos Quadros 1, 2 e 3, bem como as observações, os dados secundários e a percepção do entrevistador parecem indicar que há certa inconsistência entre a equipe de governo da Prefeitura Municipal da Cidade de Recife, no que se refere à qualidade. Isto pode ser explicado pelo possível desconhecimento técnico da questão da qualidade como elemento de gestão estratégica. Neste sentido, não houve discussão em torno do tema para o estabelecimento de diretrizes mais concretas relacionadas especificamente com administração da qualidade. Outro fator que pode ter influenciado a falta de uniformidade na visão de qualidade refere-se às divergências históricas, do ponto de vista politico-ideológico, entre os partidos que compõem a aliança que governa a cidade de Recife na gestão 1997-2000. Isto constitui mais uma evidência do argumento levantado por Vieira e Carvalho (1999): as disputas entre as coalizões de poder nas organizações podem influenciar as definições de qualidade, bem como sua operacionalização.

Os resultados apresentados apontam, ainda, uma disparidade grande entre o número de indicadores da dimensão estrutural em relação às outras duas dimensões. Este resultado pode estar relacionado a um possível desgaste das formas organizacionais do serviço público brasileiro em geral e da forma organizacional da prefeitura de Recife em particular. Isto parece indicar a necessidade de revisão de tais formas organizacionais sob bases científicas, procurando mecanismos de superação das práticas organizacionais vigentes. Acredita-se que aqui seja fundamental a análise da relação entre a organização e seu ambiente institucional (Powell e DiMaggio, 1991; Meyer e Scott, 1992).

A importância atribuída à questão dos recursos humanos foi grande. Entretanto observa-se uma distância entre o discurso e a prática, ou seja, o formalismo (Sander, 1977; Ramos, 1983). Enquanto a importância desta dimensão é fortemente enfatizada, nenhuma ação administrativa em relação a ela é efetivamente realizada.

Já os poucos indicadores relativos à dimensão política parecem apontar para uma valorização do tecnicismo em relação à política. Um discurso dessa natureza pode ser observado também na prefeitura do Rio de Janeiro, principalmente na gestão anterior à de 1997-2000. O processo de pesquisa demonstrou haver forte ligação entre o ex-prefeito do Rio de Janeiro e a atual gestão da prefeitura de Recife com relação a esta questão. Há que se salientar aqui o perigo de uma visão subideologizada da administração. Tal visão, além de prescindir do fundamental debate político na administração pública, pode representar um instrumento para a hegemonia de uma abordagem particular da gestão pública, nomeadamente a neoliberal. 


\section{Consideraçóes Finals e Sugestóes para a Introdução de Programas de Qualidade e para a Avaliação do Desempenho da Administração MuNICIPAL}

Os resultados deste estudo exploratório, bem como dos estudos de Vieira (1996, 1997), apontam a possibilidade de aplicação de práticas de administração da qualidade na administração pública (Swiss, 1992; Rees, 1992; Rago, 1994).

Ainda assim, há que se considerar uma série de peculiaridades do setor público para a implantação de um programa sistemático de administração da qualidade. São essas peculiaridades e, principalmente, alternativas para se lidar com elas que a literatura especializada na área discute pouco. Pode-se aqui usar o mesmo argumento de Storey e Sisson (1989) e afirmar que os dados apresentados são utilizados, na grande maioria das vezes, para ilustrar afirmações ou teorias (e. g. Pádua et al., 1994; Fernandes e Antunes Jr., 1994). Algumas exceções podem ser encontradas nos trabalhos de Falk (1979) e Falk e Carvalho (1996), entre outros.

Desta forma, sugerem-se três princípios que cumpre sejam observados para a implementação de um programa de administração da qualidade no setor público, conforme segue.

. Primeiro, enfatiza-se a necessidade da realização de um estudo exploratório inicial, com o objetivo de identificar a natureza do conceito de qualidade na organização objeto de análise. Tal estudo identificaria elementos importantes relativos às peculiaridades do setor a serem levadas em consideração na formulação e na implementação das diferentes etapas de um programa formal e sistemático de administração ou gerenciamento da qualidade.

Segundo, chama-se atenção para a importância de determinar os grupos organizacionais e as coalizões e seus objetivos, tendo em vista a importância da variável poder na estruturação, nas decisões e nas ações organizacionais (Vieira, 1997). A dinâmica das relações de poder e os objetivos das coalizões podem interferir diretamente nas diversas fases da aplicação de um plano de ação previamente elaborado. A identificação das coalizões e de suas dependências de poder (Pfeffer e Salancik, 1978) pode auxiliar na capacidade de ação gerencial, aumentando a margem de ações realizáveis por parte do gestor na implementação do programa de qualidade.

- Terceiro, salienta-se que a realização da análise do ambiente institucional da organização parece fundamental (Powell e DiMaggio,1991; Meyer e Scott, 1992). Ela permite a identificação das estruturas sociais, políticas e culturais que podem interferir na implementação do programa de qualidade, novamente contri- 
buindo para o aumento das possibilidades de ação gerencial por parte do administrador.

No sentido de avaliar o desempenho da administração municipal com referência ao estabelecido num plano de qualidade, sugere-se a elaboração de um questionário a partir dos indicadores levantados no estudo exploratório. Entende-se esta avaliação como processo de pesquisa longitudinal, em que seriam levados em consideração, entre alguns outros aspectos circunstanciais, os que constam a seguir.

- A importância do indicador de qualidade, com o objetivo de verificar alterações na percepção dos respondentes.

. A situação atual em relação àquele indicador na organização.

. Enfim, a situação atual em relação àquele indicador na unidade organizacional específica.

Sugere-se, ainda, que resultados não esperados, discrepâncias ou aspectos de interesse particular do administrador ou do pesquisador sejam aprofundados por meio de entrevista e com o uso de dados secundários. A utilização dos chamados indicadores sociais para acompanhamento paralelo pode garantir uma visão mais completa do desempenho da gestão pública.

Por fim, salienta-se que o desempenho do setor público deve ser entendido ou aferido por modelos que incorporem aspectos que lhe são inerentes, ou seja, objetivos conflitantes, multiplicidade de interesses e características do ambiente institucional, o que evidencia a complexidade e necessidade de mais pesquisa sobre o assunto.

\section{NOTAS}

\footnotetext{
${ }^{1}$ Os autores agradecem ao $\mathrm{CNPq}$ o apoio financeiro recebido para o desenvolvimento desta pesquisa e a Maria Ceci Misoczky, Zilá Mesquita e Eurípedes Falcão Vieira os comentários nas primeiras versões deste artigo.

${ }^{2}$ Cabe salientar que o Vice-Prefeito exerce também a função de Secretário de Cultura.

${ }^{3}$ Devido a sua pouca disponibilidade de tempo, não foi possível entrevistar o Prefeito Municipal de Recife. A Secretária de Educação também não se encontrava disponível; a entrevista relativa a essa secretaria foi realizada com a Secretária Adjunta.

${ }^{4}$ Este trabalho limita-se à análise dos indicadores gerais da administração municipal. Não se considera, portanto, os indicadores específicos para cada secretaria.
} 


\section{Referencias BibliográficAs}

BRASIL.

Programa brasileiro de qualidade e produtividade (PBQP), termo de referência. Diário Oficial da Presidência da República, Brasília, 28 jun. 1990. fls. 12456-8.

\section{BINNS, D.}

Total quality management, organization theory and the new right : a contribution to the critique of bureaucratic totalitarism. Occasional papers in Business, Economy and Society, n. 11, 1993.

DAWSON, P.;

PALMER, G.

Total quality management in Australian and New Zeland companies : some emerging themes and issues. International Journal of Employment Studies, v. 1, n. 1, p. 115-136, 1993.

FALK, J. A.

O serviço de arquivo médico e estatística na avaliação de qualidade de desempenho hospitalar. Revista de Administração para o Desenvolvimento, n. 1 , ano III, 1979.

FALK, J. A.;

CARVALHO, E.

Gestão da qualidade de serviços na área hospitalar : conceitos, cri- térios e modelo para avaliação. In: XX ENCONTRO ANUAL DA ANPAD (1996: Angra dos Reis). Anais... Rio de Janeiro : ANPAD, 1996. v. Organizações II.

FERNANDES, A. C.;

ANTUNES JR., J. A. V.

O gerenciamento da qualidade total no serviço público - o caso da Assembléia Legislativa do Rio Grande do Sul. In: XVIII ENCONTRO ANUAL DA ANPAD (1994 : Curitiba). Anais... Curitiba : ANPAD, 1994. v. Produção Industrial e de Serviços.

FERRÁNDIZ, V. R.

Plan de calidad total en el sistema sanitario : gestión de la calidad total. Revista Indicadores da Qualidade e Produtividade, p. 106123, 1992.

HACKMAN, J. R.;

WAGEMAN, R.

Total quality management : empirical, conceptual, and practical issues. Administrative Science Quarterly, v. 40, p. 309342, 1995.

HILL, S.

How do you manage a flexible firm : the total quality model. Work, Employment and Society, v. 5, n. 3, p. 395-415, 1991a. 
Why quality circles failed but total quality management might succeed. British Journal of Industrial Relations, v. 29, n. 4, p. 541-568, 1991 b.

HUERTAS, F.

O método PES : entrevista com Carlos Matus. São Paulo : FUNDAP, 1996.

LEWIS, B. R.;

MITCHELL, V.

Defining and measuring the quality of customer service. Marketing, Intelligence and Planning, v. 8, n. 6, p. 11-17, 1990.

MATUS, C.

Chimpanzé, Maquiavel e Ghandi : estratégias políticas. São Paulo : FUNDAP, 1996.

MEYER, J. W.;

SCOTT, W. R.

Organizational environments : ritual and rationality. upd. ed. London: Sage Publications, 1992.

MILES, M.;

HUBERMAN, M.

Qualitative data analysis. 2. ed. London : Sage Publications, 1994.
MISOCZKY, M. C.;

VIEIRA, M. M. F.;

LEÃO, F. P. DE S.

Dimensão política e dimensão técnica das definições de qualidade no serviço público municipal : o caso da prefeitura municipal da cidade do Recife. In : XXII ENCONTRO ANUAL DA ANPAD (1999 : Foz do Iguaçu). Anais Eletrônicos... Rio de Janeiro : ANPAD, 1999.

OAKLAND, J. S.

Total quality management. London : Heinemann, 1989.

OFFE, C.

Critérios de racionalidade e problemas funcionais da ação político-administrativa. In:

Problemas estruturais do estado capitalista. Rio de Janeiro : Tempo Brasileiro, 1984.

PÁDUA, G. G. et al.

Qualidade e produtividade nos serviços médico-hospitalares : a metodologia de desenvolvimento e implantação do programa de controle de qualidade total - P.C.Q.T. - no Hospital das Clínicas da Faculdade de Medicina de Ribeirão Preto da Universidade de São Paulo - H.C.F.M.R.U.S.P. In: XVIII ENCONTRO ANUAL DA ANPAD (1994: Curitiba). Anais... Curitiba : ANPAD, 1994. v. Produção Industrial e de Serviços. 
PARASURAMAN, A.;

ZEITHAML, V. A.;

BERRY, L. L.

A conceptual model of service quality and its implications for future research. Journal of Marketing, v. 49, p. 41-50, 1985.

PEFFER, J.;

SALANCIK, G. R.

The external control of organizations : a resource dependence perspective. New York : Harper \& Row, 1978.

PINHO, J. A. G.;

SANTANA, M. W.;

CERQUEIRA, M. B.

Gestão pública em busca da cidadania : experiências de inovação em Salvador. Cadernos de Gestão Pública e Cidadania, v. 5, 1997.

PIORE, M.;

SABEL, C.

The second industrial device : possibilities for prosperity. New York : Basic Books, 1984.

POLLIT, C.

Managerialism and the public services : cuts or cultural change in the 1990s? 2. ed. Oxford : Blackwell, 1993.

POLLITT, C.;

BOUCKAERT, G.

Defining quality. In: POLLITT,
C.; BOUCKAERT, G. (Eds.). Quality improvements in European public services. London: Sage Publications, 1995.

POWELL, W. W.;

Di MAGGIO, P. J. (Eds.).

The new institutionalism in organizational analysis. Chicago : University of Chicago Press, 1991.

RAMOS, A. G.

Administração e contexto brasileiro : esboço de uma teoria geral da administração. 2. ed. Rio de Janeiro : FGV, 1983.

RAGO, W. V.

Adapting total quality management (TQM) to government : another point of view. Public Administration Review, v. 54, n. 1, p. 61-64, 1994.

REES, J. L.

Managing quality in public services. In: DUNCAN, C. (Ed.). The evolution of public management : concepts and techniques for the 1990s. London : MacMillan, 1992.

SANDER, B.

Educação brasileira : valores formais e valores reais. Rio de Janeiro : Pioneira, 1977. 
SPINK, P.

Descentralização : luto ou luta. In: FISCHER, T. (Org.). Poder local, governo e cidadania. Rio de Janeiro : FGV, 1993.

STOREY, J.K.;

SISSON K.

Looking to the future. In: STOREY, J. (Ed.). New perspectives on human resource management. London : Routledge, 1989.

SWISS, J. E.

Adapting total quality management (TQM) to government. Public Administration Review, v. 52, n. 4, p. 356-362, 1992.

VIEIRA M. M. F.

Poder, objetivos e instituições como determinantes da definição de qualidade em organizações brasileiras e escocesas. Revista de Administração Contemporânea, v. 1, n. 1, p. 07-34, 1997.

Quality without quality management : an exploratory research in a public organisation. In: XX ENCONTRO ANUAL DA ANPAD (1996 : Angra dos Reis). Anais... Rio de Janeiro : ANPAD, 1996a. v. Organizações II.

VIEIRA, M. M. F.;

CARVALHO, C. A. P.

Qualidade e objetivos : implicações teóricas e metodológicas para a análise das organizações. In: VIEIRA, M. M. F.; OLIVEIRA, L. M. B. (Orgs.). Administração contemporânea : perspectivas estratégicas. São Paulo : Atlas, 1999. 